\title{
FOTOGRAFI SUREALISME \\ Visualisasi Estetis Citra Fantasi Imajinasi
}

\author{
Soeprapto Soedjono \\ Jurusan Fotografi, Fakultas Seni Media Rekam, ISI Yogyakarta \\ Jalan Parangtritis Km 6,5 Sewon, Bantul, Yogyakarta \\ No. Hp.:+081578925950, E-mail: soeprapto.soedjono@yahoo.com
}

\begin{abstract}
ABSTRAK
Sebagaimana yang terjadi pada ranah seni sastra dan seni rupa, pengaruh surealisme sebagai moda artistik penciptaan karya seni, ternyata juga memengaruhi perkembangan bentuk dan genre baru di ranah fotografi. Sebagai bagian dari upaya-upaya penciptaan karya kreatif fotografis, beberapa fotografer menggunakan berbagai aspek dalam domain fotografi untuk juga bisa menampilkan karya-karya yang bernuansa surréal dan terkesan bersifat surealistis dengan berbagai teknikteknik penciptaan visualnya. Prinsip-prinsip surealisme yang berkaitan dengan upaya memadukan elemen visual yang nyata dan yang bersifat tidak nyata (virtual, dream-like, fantasy) dalam karya-karya fotografi merekamenghasilkan sebuah fenomena 'keraguan' dalam menyikapi karya fotografinya. Hal ini terjadi karena yang selama ini karya fotografi diyakini sebagai medium penghasil karya seni visual yang nyata/realis dan merupakan satu bentuk representasi realitas yang faktual telah menjadi 'ragu' terhadap hasil karya fotografi surrealistic yang diciptakannya. Visualisasi bentuk-bentuk yang riil tertampilkan bertentangan dengan kelayakan konvensi logika visual alamiah realisme media fotografi yang ada. Namun, secara artistik tentunya kehadiran fotografi surealistik ini bisa dijadikan sebagai salah satu upaya alternatif penampilan visual karya seni fotografi yang ekspresif. Dalam arti bahwa ranah fotografi juga memiliki moda ungkapan ekspresif estetik yang juga memiliki kemungkinan untuk mengekplorasi aspek-aspek dunia mimpi bawah sadar, fantasi, yang bernuansa simbolisme visual dalam kancah pengembangan budaya visual yang bernilai 'nyata - tidak nyata'.
\end{abstract}

Kata kunci: fotografi surealisme, visualisasi estetis, citra fantasi imajinasi

\begin{abstract}
Surrealism Photography: Aesthetic Visualization of the Imagination Fantasy Imagery. As appeared in the sphere of literary and fine arts, the influence of surrealism as an artistic mode for the creation of works of art, apparently it also influences the development of new forms and genres in the sphere of photography. As part of the efforts to create photographic creative works, some photographers use various aspects in the photographic domain to also be able to present works which are surreal in nature and seem surrealistic in their various visual creation techniques. The principles of surrealism are associated with the attempts to combine visual elements which are real and not real (virtual, dream-like, fantasy) in photography works produce a phenomenon of 'doubt' in addressing the photographic work. This happens because all this time photography is believed to be a medium that produces visual art works that are real or realistic and is a form of factual reality representation which has become 'doubtful' of the surrealistic photographic works that it creates. The visualization of the real forms that appear is contrary to the feasibility of the natural visual logic conventions of the realism of the existing photographic media. However, artistically, the presence of this surrealistic photography can be used as an alternative attempt for the visual appearance of expressive photographic artworks. In the sphere of photography, it makes sense that it has an aesthetic expressive mode of expression which also has a possibility to explore the aspects of the subconscious self, fantasy, having the nuance of visual symbolical in the domain of developing visual culture which could be valued as 'real-not real'.
\end{abstract}

Keywords: surrealism photography, aesthetic visualization, imagination fantasy imagery 


\section{PENDAHULUAN}

Sekitar 80 tahun setelah ditemukannya fotografi di Eropa, telah berkembang satu moda visualisasi artistik yang merupakan manifestasi perkembangan gaya tampil seni rupa yang banyak dipengaruhi oleh wacana psikologi dan kedalaman pemikiran kemanusiaan melihat alam lingkungan sekitarnya. Awal abad XX ini banyak dipengaruhi oleh beberapa pemikiran dan kejadian yang secara pasti telah memberikan stimulasi bagi para ilmuwan, filsuf, dan seniman untuk berlomba dalam mengantisipasi perkembangan dan tantangan zamannya. Konon kemunculan moda pendekatan artistik surealistik dalam bidang seni rupa ini salah satunya merupakan responS terhadap berakhirnya Perang Dunia I di Eropa pada waktu itu yang terus berkembang sampai awal Perang Dunia II. Di samping juga merupakan kelanjutan perkembangan artistik yang ada pada zaman tersebut seperti yang terlihat pada kecenderungan gaya estetis individual beberapa seniman. Antara lain, Marc Chagall yang mengembangkan gaya lukisannya dengan menggabungkan aspek fantasi dan simbolisme sebagaimana dinyatakan oleh Preble (1989:406) bahwa: “...Chagall continued to create paintings based on fantasy and symbolism, and in this sense his paintings continue to be associated with surrealism."

Demikian juga yang dilakukan oleh para pelukis Eropa lain pada saat itu, seperti Salvador Dali, Max Ernst, Joan Miro, Roberto Mata, dan beberapa lainnya yang menampilkan karya yang bertentangan dengan rasio dan akal logika serta menyiratkan nuansa dunia mimpi dan imajinasi bawah sadar manusia (dreams and subconscious).

Secara etimologis istilah 'surrealisme' tersebut berasal dari kata dalam bahasa Perancis 'surréalisme' - gabungan dua kata 'sur' (super, beyond or above) + 'réalisme' sehingga dapat diterjemahkan menjadi super-realis, lebih dari sekadar realis, atau lebih dari keadaan senyatanya. Kemunculannya sebagai istilah kali pertama digunakan oleh seorang dramawan Perancis, Guillaume Apollinaire untuk menamai kata pengantar karya dramanya Le Mamelles de Tiresias (The Breast of Tiresias) yang dipentaskan pada tahun 1917. Surealisme dalam teater ini juga memengaruhi beberapa bentuk konvensi artistik teater yang menggabungkan dua elemen simbolisme dan nonrealisme. Hal tersebut terlihat dalam pementasan beberapa genre teater, antara lain Theatre of Cruelty (Antonin Artaud) dan gerakan Theatre of the Absurd pada tahun-tahun berikutnya yang berpusat di Paris. Namun, dalam perkembangannya sebagai sebuah moda tampilan kesenian, surealisme lebih banyak memengaruhi perkembangan seni rupa dan kemudian memberikan dampak artistik pula dalam ranah penciptaan seni fotografi. Khususnya moda visual ini memberikan opsi alternatif dalam memperkaya wacana dan praksis fotografi sebagai sebuah entitas karya seni visual.

Sebagai suatu paham dan gerakan seni rupa, surealisme merupakan suatu bentuk manifestasi 'perkembangan' artistik dari Dadaisme di Eropa. Hal ini dibuktikan oleh penganjur dan tokoh pencetusnya, André Breton, yang sebelumnya juga aktif dalam gerakan senirupa Dadaisme. Manifesto Surealisme (Manifeste de Surréalisme) secara teoretis dan filosofis yang kali pertama dinyatakan dan dipublikasikan oleh André Breton pada tahun 1924 di Paris, Perancis, yang kemudian dianggap sebagai tahun kelahiran gerakan surealisme di Eropa. Adapun pernyataan tersebut sekaligus memberikan kejelasan tentang moda artistik yang 
dinyatakan oleh Breton sebagai "pure psychic automatism". Suatu cara dalam penciptaan karya seni yang didasari oleh spontanitas kejiwaan yang lebih mengutamakan ekspresi bawah sadar manusia yang kadang mengurangi nilai logika dan nalarnya demi mengutamakan nilai 'rasa' penciptaannya. Jiwa dari moda gaya ini nantinya akan tecermin pada karya-karya seni surealisme yang ada baik itu dalam seni teater, seni rupa, maupun nantinya pada seni fotografi. Hal ini secara jelas didukung oleh pernyataan Fleming bahwa:

\section{The surrealist manifesto} of 1924 proclaimed that the style was based on "pure psychic automatism by means of which one sets out to express verbally, in writing or in any other manner, the real functioning of thought without any control by reason or any aesthetic or moral preoccupation" (Fleming, 1980:424).

Penjelasan Fleming tersebut lebih jauh mengidentifikasi ciri-ciri moda estetik surealisme - 'superrealism' yang menyiratkan keluasan kenyataan dari suatu tampilan kasat mata yang bisa dipersepsi sebagai hal yang tidak logis yang terdapat di alam bawah sadar dunia mimpi manusia. Para kaum surealis meyakini tentang superioritas suatu tampilan impian dibandingkan dengan keadaan realitas kesadaran manusia. Sebagaimana surealisme yang dinyatakannya sebagai:

\footnotetext{
“...implies a greater reality underlying the world of appearances, an illogical, subconscious dream world beyond the logical, conscious, physical one...the superior reality of the dream to the waking state, of fantasy to reason, of the subconscious to the conscious" (Fleming, 1980:424).
}

Sebagaimana André Breton sebagai penganjur manifesto surealisme juga menyatakan tentang adanya keindahan yang terdapat di dalam dunia mimpi yang menciptakan adanya fantasi atau disebutnya sebagai suatu 'keindahan nyata tetapi tidak nyata dalam dunia impian' - the convulsive beauty of dreams. Suatu nilai keindahan yang berasal dari bawah sadar manusia yang dicetuskan secara spontan tanpa ada pertimbangan nalar yang terencana secara pasti dan lebih mengutamakan kehadiran tampilan imajinatif subjek karya seninya. Dengan demikian, dapat ditengarai secara lebih kongkrit bahwa tampilan surealistis menawarkan suatu alternatif tampilan baru bagi dunia seni pada waktu itu yang tidak harus identik dengan tampilan lingkungan alam sekitar yang sekian lama diacu dan sudah dipraktekkan oleh para seniman secara lebih subjektif lagi. Persepsi sosial karya seni pada masa itu mendapatkan 'tantangan baru' untuk menghadirkan sebuah bentuk karya seni yang beriringan dengan perkembangan dan inovasi teknologi yang ada.

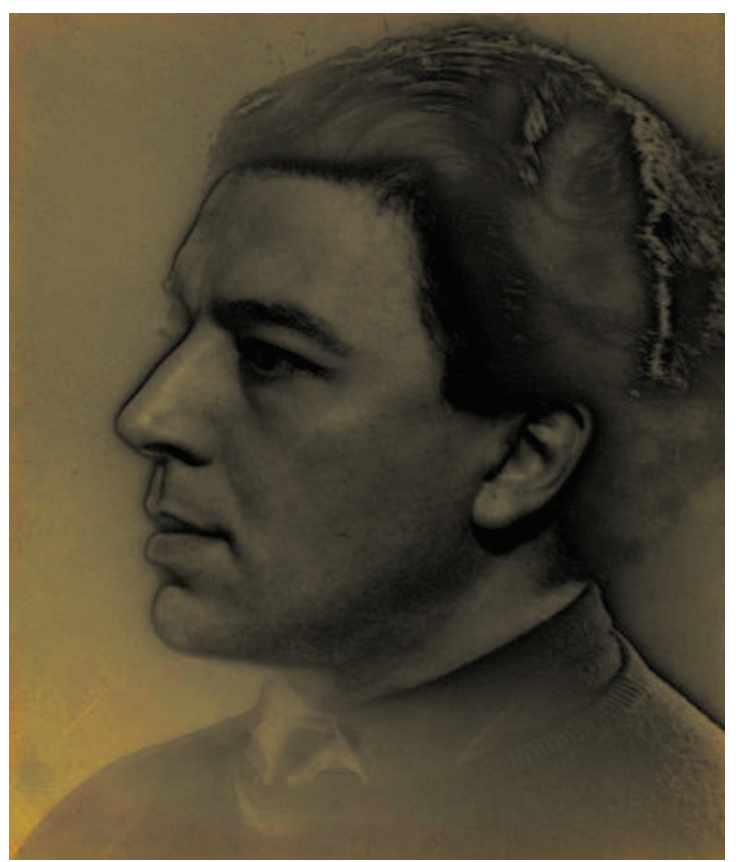

Gambar 1 “André Breton” by Man Ray (1929) 
André Breton adalah seorang pemikir, kritikus sastra, seniman, pengarang, dan tokoh intelektual Perancis yang menyatakan dan memformulasikan Manifesto Surealisme Manifestoes of Surrealism (1924) di Paris, Perancis. Adapun teori-teori André Breton banyak dipengaruhi oleh penganjur pakar psikologi dan psikoanalisisnya Sigmund Freud tentang masalah-masalah kejiwaan yang berkaitan dengan mimpi, fantasi, imajinasi, dan kegiatan bawah sadar (dreams \& subconscious mind) manusia. Dalam perkembangannya, surealisme sebagai suatu moda artistik yang bermula di bidang seni sastra ternyata lebih banyak berkembang pada ranah senirupa/seni visual termasuk seni fotografi. Secara visual elemen-elemen yang ditampilkan dalam karya seni lukis terlihat dalam penggunaan bentukbentuk imajinatif dan simbolistis disertaitampilan realistik yang tidak rasional dan mengganggu kesadaran logika visual. Bisa juga dikatakan bahwa hal tersebut merupakan suatu potensi atau kualitas keindahan yang terdapat pada bentuk-bentuk visual yang tertampilkan sebagai citra visual hasil khayalan imajinasi manusia. Dalam konteks inilah upaya para seniman dalam mengekspresikan kemampuan teknis dan estetis mereka menemui satu saluran pengejawantahan baru untuk mencoba memvisualkan ide dan konsep kreatifnya dalam berbagai medium

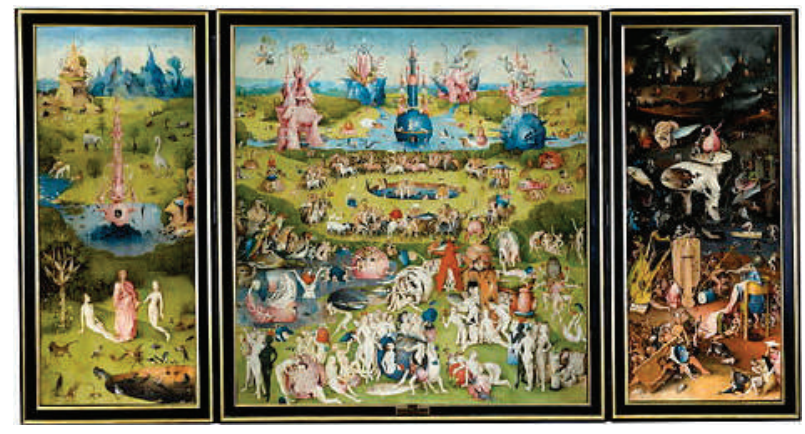

Gambar 2 "The Garden of Earthly Delights", Hieronymus Bosch (c. 1515)
Sebetulnya, sebagai suatu ide penampilan secara visual hal ini pernah ditampilkan oleh beberapa seniman lukis pada beberapa abad sebelumnya. Di antaranya bisa disebutkan karyakarya yang menampilkan suasana 'surreal' yang berkonotasi dalam kehidupan imajinatif di alam baka, khususnya kehidupan bagi para pendosa di neraka. Sangat dimungkinkan apa yang tervisualkan tersebut merupakan interpretasi visual dari kitab suci keagamaan yang sengaja diberdayakan bagi upaya penguatan iman dengan bayangan ketakutan dan kengerian suasana yang akan dihadapi oleh para pendosa di akhirat kelak. Tampilan tersebut terlihat dalam beberapa karya Hieronymush Bosch, seorang pelukis dari Belanda pada awal abad XVIyang dikenal dengan karya-karyanya bernilai 'fantastic imagery' yang bernarasikan nilai-nilai keagamaan. Sebagaimana yang terlihat dalam karyanya yang berbentuk tryptich (tiga-panel) 'The Garden of Earthly Delights (1515). Dalam lukisan tersebut tergambarkan tokoh-tokoh dunia akherat yang juga dipenuhi oleh figur-figur manusia yang ditampilkan bersama para makhluk binatang dan sosok imajinatif berdasarkan hasil imajinasi dan fantasi pelukisnya. Adapun bentuk tampilnya yang berupa tryptich tiga panel diasumsikan mengacu pada nilai filosofi Kristiani Trinity yang sering dijumpai di dalam gereja.

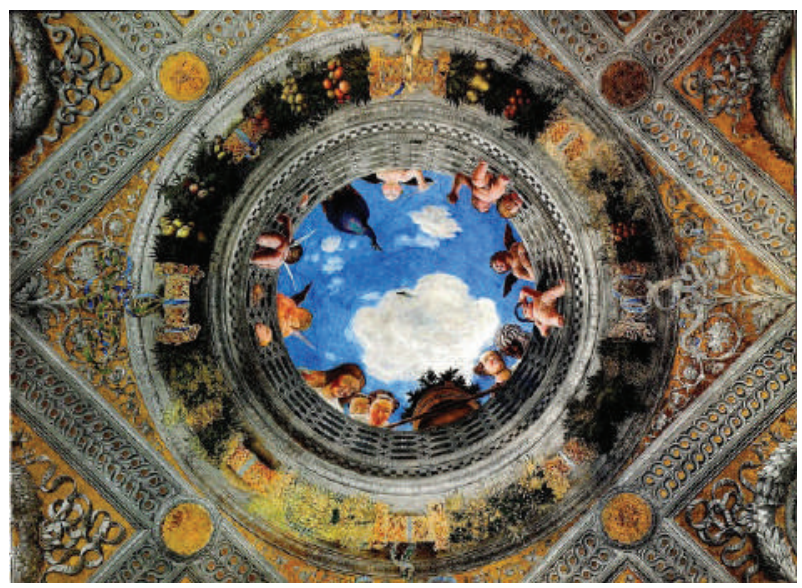

Gambar 3 Karya Fresco ceiling Andrea Mantegna dengan teknik foreshortening (c. late Cuatrocento) 
Meskipun secara resmi surealisme lahir dari manifesto André Breton pada tahun 1924, sebagai fenomena gerakan artistik senirupa sudah terlihat pada beberapa tahun sebelumnya. Hal ini terlihat dalam karya-karya seni lukis 'futurist' Italia, Carlo Carra (1881-1966) dan Giorgio de Chirico (1888-1978) pada tahun 1911-1912. Mereka mencetuskan pola artistik mereka dengan menyebutnya sebagai 'Pittura Metafisica - Methaphysical Picture' atau Lukisan Metafisik. Sebagaimana yang terlihat dalam aktivitas berkarya mereka, dua pelukis ini menyepakati sebagaimana yang dinyatakan oleh Soedarso Sp., bahwa:

“... segala sesuatu memiliki dua aspek ialah aspek yang biasa sebagaimana kita lihat sehari-hari (dan bisa ditangkap oleh semua orang) dan aspek metafisis yang hanya bisa ditangkap oleh orang-orang tertentu pada saat tertentu pula (transedental)" (Soedarso Sp., 2000:130).

Pittura Metafisica ini '...nanti akan membuka jalan bagi lahirnya kelompok yang lebih luas lagi, ialah kelompok surealisme.' Oleh karena itu pulalah, Soedarso Sp. menyebut Pittura Metafisica sebagai 'Pengawal Surealisme'. Dalam arti bahwa surealisme muncul bukan sesuatu yang tibatiba, tetapi prinsip-prinsip estetika visualnya merupakan perkembangan yang diawali oleh gaya moda artistik yang sudah ada sebelumnya. Sebagaimana juga yang tampak dalam karyakarya lukis Giorgio de Chirico dan Carlos Carra yang dianggap memiliki kesan dan tampilan moda visual surealistik berikut ini.

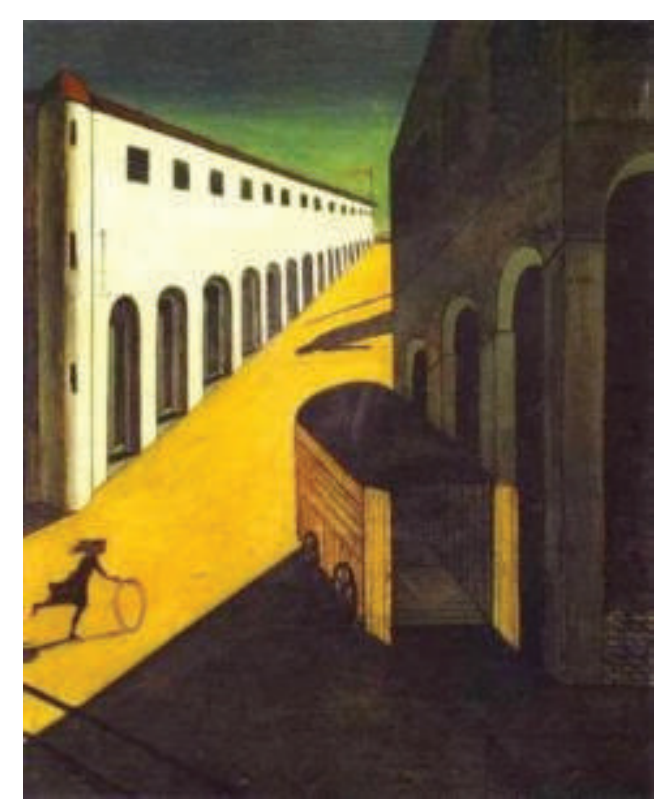

Gambar 4 "Melancholy \& Mystery of the Street" - G.de Chirico (1914)

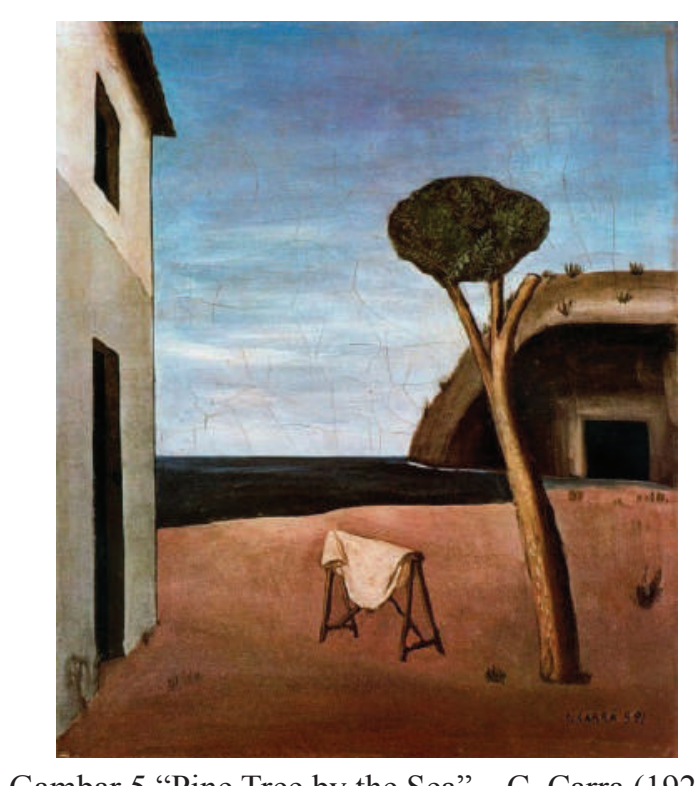

Gambar 5 "Pine Tree by the Sea" - C. Carra (1921)

Perkembangan surealisme dalam seni rupa menghasilkan dua gaya yang mengemuka dan terlihat dalam teknik visualisasi pemilihan elemen-elemen visual yang diaplikasikan dalam karya-karyanya. Menurut Soedarso Sp. (2000:133) bahwa dua tendensi gaya visual seni lukis ini disebutnya sebagai surealisme ekspresif yang terwakili oleh dua pelukis Spanyol, Joan Miro dan Carlo Carra; serta surealisme murni yang terlihat dalam karya-karya seni lukis Salvador Dali yang juga seorang pelukis dari negara yang sama. 


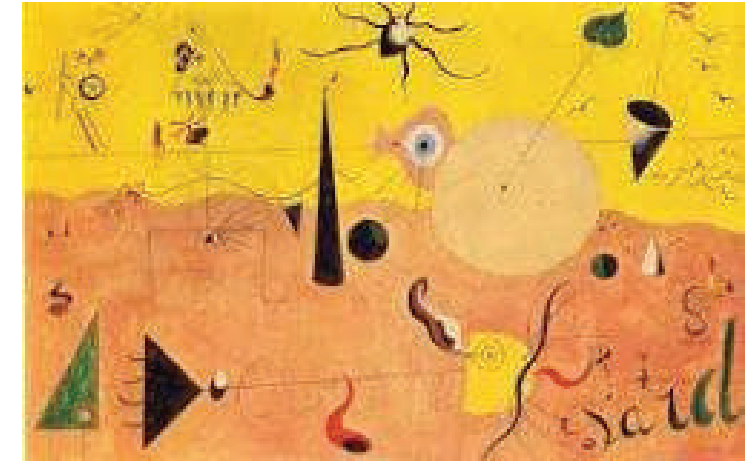

Gambar 6 "Catalan Landscape”, (1923-24) - Joan Miró

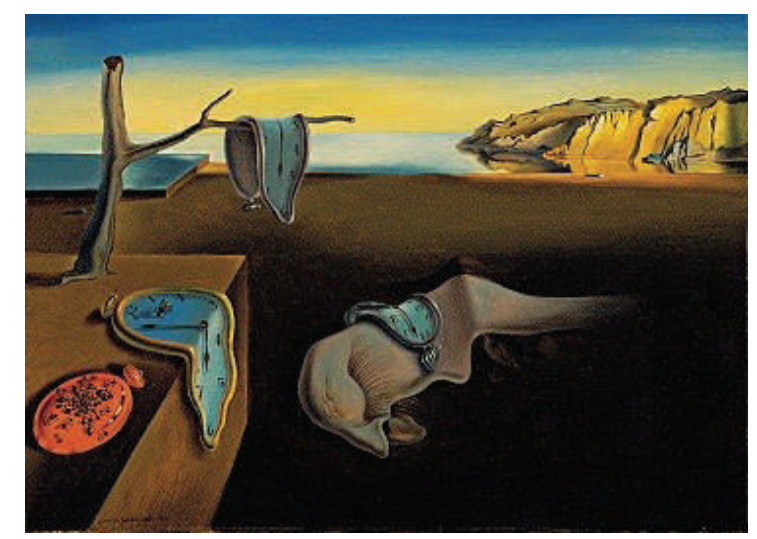

Gambar 7 "Persistence of Memory", (1931) - Salvador Dali

Di antara gaya visual kedua pelukis ini, tampaknya secara visual karya Salvador Dali banyak memengaruhi karya-karya surealisme fotografi. Hal ini tiada lain karena ada tendensi kedekatan visual realisme Dali yang mirip dengan karya fotografi, meskipun ditampilkan di luar nalar realisme itu sendiri. Dalam karyanya tersebut, Dali menjelaskan bahwa itu merupakan 'handpainted dream photograph' (Fleming, 1980:425). Sebuah karya fotografi yang bernuansa lukisan tangan seperti dalam mimpi. Sementara itu, Preble (1989:408) menyebut bahwa dua pelukis Spanyol ini (Miró dan Dali) dalam konteks gaya surealismenya dibedakan karena gaya moda tampil surealismenya berlawanan satu sama lain ('opposite tendencies operating in surrealism'). Bahwa tampilan karya Miró disebutnya bertendensi 'abstract surrealism' sedangkan karya-karya Dali karena tampilannya yang ilusif dan lebih mendekati kenyataan tampilan realisme fotografis citra imaji alam mimpi (nearphotographic dream images) dikatakannya sebagai 'representational surrealism'. Sebuah perbedaan dalam cara menampilkan kreativitas dalam berkarya surealisme seni lukis dengan teknis penciptaan yang secara visual memiliki nilai artistik yang berbeda pula.

\section{SUREALISME DALAM RANAH FOTOGRAFI}

Sebagaimana yang terjadi pada ranah seni sastra dan seni rupa, pengaruh surealisme sebagai moda artistik penciptaan karya seni, ternyata juga memengaruhi perkembangan bentuk dan genre baru di ranah fotografi. Sebagai bagian dari upaya-upaya penciptaan karya kreatif fotografis, beberapa fotografer menggunakan berbagai aspek dalam domain fotografi untuk juga bisa menampilkan karyakarya yang bernuansa surréal dan terkesan bersifat surealistis dengan berbagai teknikteknik penciptaan visualnya. Prinsip-prinsip surealisme berkaitan dengan upaya memadukan elemen visual yang nyata dan yang bersifat tidak nyata (virtual, dream-like, fantasy) dalam karyakarya fotografi mereka sehingga menghasilkan sebuah fenomena 'keraguan' dalam menyikapi karya fotografinya. Hal ini terjadi karena yang selama ini karya fotografi diyakini sebagai medium penghasil karya seni visual yang nyata/realis dan merupakan satu bentuk representasi realitas yang faktual telah menjadi 'ragu' terhadap hasil karya fotografi surrealistic yang diciptakannya. Visualisasi bentuk-bentuk yang riil tertampilkan bertentangan dengan kelayakan konvensi logika visual alamiah realisme media fotografi yang ada. Dengan kata lain disebut oleh Ian Jeffrey sebagai, "States of mind were a challenge to photography which 
was a naturalistic medium" (Jeffrey, 2008:152). Namun, secara artistik tentunya kehadiran fotografi surealistik ini bisa dijadikan sebagai salah satu upaya alternatif penampilan visual karya seni fotografi yang ekspresif. Dalam arti bahwa ranah fotografi juga memiliki moda ungkapan ekspresif estetik yang juga memiliki kemungkinan untuk mengekplorasi aspekaspek dunia mimpi bawah sadar, fantasi, yang bernuansa simbolisme visual dalam kancah pengembangan budaya visual yang bernilai 'nyata - tidak nyata'. Dengan kata lain, surreal fotografi merupakan karya yang realistik secara visual tertampakkan bertentangan dengan rasionalitas logika pemirsanya - lebih tegasnya lagi dikatakan sebagai hal yang 'menghancurkan rasio atau akal sehat' seperti apa yang telah disebutkan oleh Bowker (2013:6) sebagai 'rational destruction'.

Layak untuk disimak sebagai referensi karya fotografi hitam putih yang terlihat dalam karya-karya fotografi Jerry Uelsman yang bernuansa surealisme berikut ini. Kedua karyanya merupakan karya rekayasa di kamar gelap yang memadukan realisme dua objek fotonya menjadi satu tampilan karya fotografi hitam putih yang mengesankan tampilan visual subjek foto yang 'unrealistic' meskipun diciptakan dengan media fotografi. Tampilan visual karya Jerry Uelsman ini menawarkan visualisasi medium fotografi yang berlandaskan imajinasi sang fotografer untuk mencoba memanipulasi dan memadukan nuansa realism yang menciptakan tampilan visual yang berlandaskan pada aspek formalism yang tidak harus sesuai dengan logika nyata dari hasil akhir karya fotografinya. Dalam konteks lain, karyakarya tersebut dapat dikategorikan juga sebagai karya fotografi ekspresif karena merupakan representasi ide, konsep, dan ekspresi sang fotografernya dalam berkarya fotografi. Konon karya moda gaya surealisme Jerry Uelsman ini banyak menginspirasi karya-karya fotografi masa kini dengan teknik digital yang secara teknis mempermudah ide-ide kreatif surealisme dalam pelaksanaan implementasi visualnya.

Apa yang tertampakkan dalam karyakarya Jerry Uelsman ini secara wacana terbingkai dan bersinggungan dengan teori Walter Benjamin tentang istilah 'postauratic' yang diungkapkannya dalam artikelnya bertajuk "The Work of Art in the Age of Mechanical Reproduction" dalam Illuminations (Pimlico, 1999). Istilah tersebut dinyatakannya berkaitan dengan posisi karya seni yang sesudah melalui proses reproduksi mengalami apa yang disebutnya dalam posisi 'post-auratic' (pascaaura). Sebuah pandangan masyarakat yang terkait dengan sebuah karya seni yang memiliki keunikannya sendiri (aura) telah berubah nilai posisi kehadirannya setelah direproduksi dengan tujuan yang mungkin berbeda dari ide, dan konsep semula karya seni itu diciptakan pada awal kehadirannya. Setelah melalui proses reproduksi nilai tampil dari karya yang ada bisa berkurang karena adanya perubahan medium yang digunakan untuk kehadiran barunya tersebut. Hal ini ditengarai oleh Walter Benjamin sebagai berkurangnya nilai tampil yang diapresiasi oleh masyarakat: " The situations into which the product of mechanical reproduction can be brought may not touch the actual work art, yet the quality of its presence is always depreciated" (Benjamin, 1999:215). 


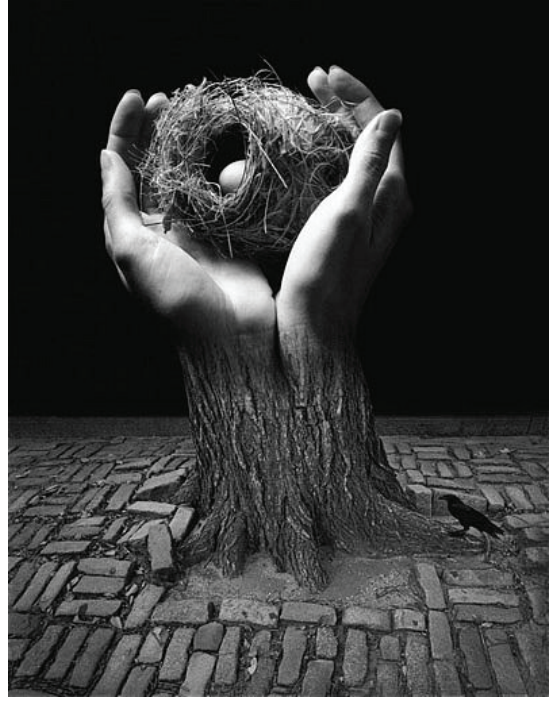

Gambar 8 “Journey into Night” (2006), J. Uelsman

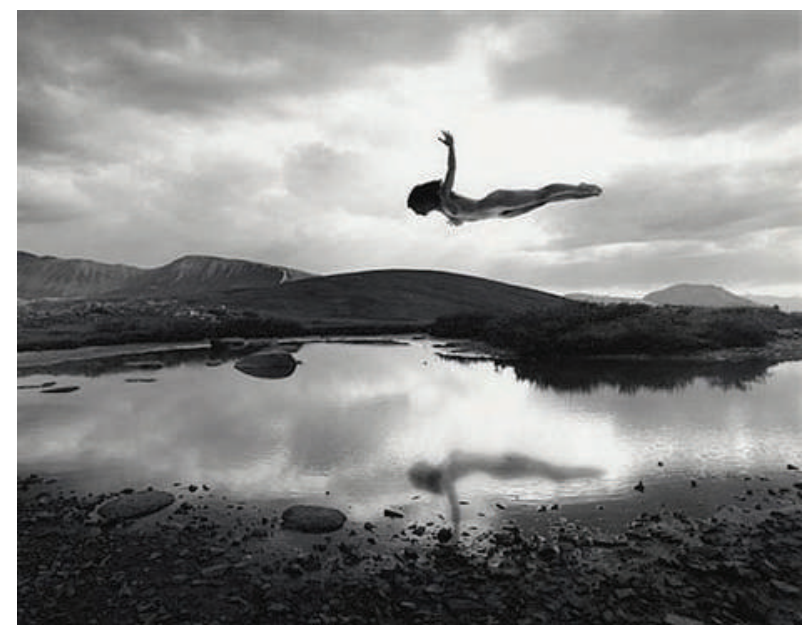

Gambar 9 "Naked Flying” (1987), J. Uelsman

Sebuah lukisan Leonardo da Vinci "Monalisa"- La Gioconda (c.1503) telah berubah 'aura' seninya setelah lukisan tersebut dihadirkan sebagai elemen ilustrasi dalam tampilan poster iklan yang mempromosikan produk atau jasa tertentu. Kedudukannya sebagai sebuah karya seni lukis setelah direproduksi menjadi elemen ilustrasi pada sebuah desain grafis telah merubah posisinya sebagai sebuah karya seni yang 'post-auratic' dan 'depreciated' nilai tampil barunya tersebut dibandingkan dengan karya aslinya sebagai karya seni lukis.

Dalam konteks karya fotografi Jerry Uelsman, penggabungan dua atau lebih karya foto dengan teknik' dark-room montaged' proses dalam satu karya dapat dipandang sebagai karya seni yang 'post-auratic' juga dengan catatan bahwa karyanya justru telah meningkatkan nilai dan opsi praksis estetis fotografi. Untuk itu, konsep dan tujuan perancangan karyanya memang dari awal dimaksudkan sebagai karya yang 'direproduksi' secara teknikal, namun untuk kembali dihadirkan menjadi satu karya foto yang surealistis sifatnya. Dalam konteks ini karya fotografi surealistik yang merupakan paduan subjek fotografis tersebut bukannya bernilai 'depreciated', tetapi malah bernilai sebaliknya sebagai karya fotografi yang bernilai 'appreciated' kreatif estetis karena nilai 'nyata tidak nyatanya' sebagai karya fotografi surealistik.

Dalam wacana yang lain, bagi seorang Irving Singer, seorang pengajar Philosophy of Film dari Massachusetts Institute of Technology (MIT), USA, menyatakan bahwa sebuah film merupakan media transformasi. Dia menyatakan bahwa para pemikir seperti Eisenstein, Arnheim, dan Balázs mendukung pernyataan bahwa film adalah karya seni yang menggunakan konsep transformasi tersebut:

"...film becomes an art

by transforming what is real instead of merely reproducing or recording it. Since they identify reproduction with indiscriminate photography, the formalists stress the role of technical maneuvers that alter reality for the sake of aesthetic creativity" (Singer, 1998:4).

Terutama kaitannya dengan media fotografi yang juga melakukan berbagai cara secara teknis 'mengubah' nilai tampil realitas formalnya bagi kepentingan kreatifitas estetis. Konsep ini merupakan bagian dari upaya teknikal yang dilakukan oleh Jerry Uelsman dan 
fotografer lainnya dalam menciptakan karyakarya fotografi yang bernuansa surealistik.

Singer juga menyatakan bahwa film sebagai karya seni terlibat langsung dengan apa yang dikatakannya sebagai sebuah wacana pertentangan yang disebutnya sebagai Realism vs Formalism (Singer, 1998:1-11). Hal ini juga bersifat analogous dengan apa yang terjadi dalam karya fotografi surealistik yang mencoba 'meninggalkan' sifat aslinya sebagai media yang hanya menciptakan bentuk-bentuk dokumentatif realism saja menjadi karya fotografi yang bernuansa ekspresi formalism. Keadaan ini memberikan peluang lebih luas bagi ranah fotografi untuk juga bisa berkiprah di ranah seni visual 'fine-arts' sebagai karya seni yang bernuansa fotografi ekspresif, yaitu karya seni fotografi yang lebih mengutamakan nilai 'subjektifitas' pribadi sang fotografer yang secara mandiri pemilik ide dan konsep pribadi dalam setiap penciptaan karya seni fotografinya.

Adapun dari sisi penciptaan kreatifnya, sebuah karya fotografi yang bernuansa surealistis bisa dikreasi dengan menggunakan ide dan konsep 'dualisme' yang berorientasi pada dua tataran estetika fotografi baik ideational maupun technical sebagai berikut.

1. Nilai visual estetis yang 'embedded' pada diri objek fotonya dengan tampilan keberadaannya sudah memiliki tampilan yang bernilai dan bernuansa surealistis. Sang fotografer tinggal merepresentasikan dan mengembangkannya sesuai subjektivitas kepekaan rasa estetisnya baik itu yang menyangkut paduan komposisinya maupun merekayasa angle pemotretannya 'in-situ' agar representasi karya fotonya sesuai dengan ide dan konsep surealistisnya. Subjektivitas sang fotografer ('the Man behind the Camera') yang menerapkan konsep tertentu dalam proses penciptaannya. Dua jenis orientasi sikap pandang ideasional secara teortis ini sangat mungkin saling bertautan dan besar kemungkinan terimplementasi secara konseptual dalam tampilan visualisasi satu karya fotografi yang bernilai surealistik. Kecenderungan ini akan memberikan kesempatan bagi sang fotografer untuk mengeksplor beragam kemungkinan secara tehnis sehingga apa yang dilakukannya secara terus-menerus membentuk gaya tampil pribadi yang terwakili oleh semua karya yang diciptakannya.

2. Secara teknikal, terciptanya tampilan visual karya fotografi surealistis dapat diupayakan dengan konsep proses pemotretan dengan segala teknik dan penggunaan beragam apparatus fotografi yang dibutuhkan dalam penciptaan kreatifnya. Di samping itu, pengupayaan dalam proses kreatif 'montage' kamar gelap dan atau kamar terang baik yang dilakukan secara manual maupun digital yang didukung oleh beragam piranti lunak (softwares) yang tersedia merupakan proses teknikal yang berpotensi dalam proses kreatif karya foto surealistik. Termasuk juga dalam ranah teknikal ini adalah upaya penampilan akhir dari karya tersebut dihadirkan. Baik itu meliputi dalam bentuk media terpilih yang disesuaikan dengan konsep dan tujuan karya fotonya dihadirkan kepada khalayak maupun bagaimana format pilihan untuk menghadirkan karya tersebut dilaksanakan karena setiap media tampil yang digunakan tentu memiliki beragam aspek teknikal dalam penampilan akhirnya. 
Keberadaan suatu objek foto yang memiliki potensi baik secara estetis maupun secara maknawi yang tersirat dapat memicu seorang fotografer untuk mengabadikannya dan menjadikannya sebagai sebuah karya foto yang surealistis. Untuk hal ini dibutuhkan 'jam terbang'/pengalaman dan kepekaan untuk dapat mempersepsi suatu stimulus visual yang dimiliki oleh satu atau lebih objek foto untuk dijadikan sebagai karya foto yang surealistis. Potensi visual objek fotonya sendiri sudah menawarkan kepada sang fotografer tanpa harus banyak merekayasa atau memberdayakan dengan berbagai teknik selain 'just point \& shoot' atau 'SOOC: Straight Out Of the Camera' untuk mengabadikan objek fotonya guna ditampilkan sebagai sebuah karya foto dengan bobot subjek surealistis yang memadai. Hal ini pun memberikan kemungkinan pada para fotografer yang melakukan 'candid photography' tanpa harus memanipulasi karya fotografinya. Sebagaimana yang dikatakan oleh Clark yang menyebut Eugene Atget dan Henry Cartier Bresson sebagai fotografer surrealists:

$$
\text { "...the surreal is }
$$

established in terms of what has been directly photographed. Thus, Cartier Bresson and Atget (much celebrated by the surrealists at the time) can be seen as surrealists, even though they do not manipulate their images; rather, they find the condition in the scene itself" (Clarke, 1997:112).
Karya kedua 'forerunners of surrealism and modern approached to the art of photography') ini terlihat pada dua karya mereka. Eugene Atget (1857-1927) dengan karyanya ("Church of St, Gervais, c.1903, Paris) dalam salah satu karya serial dokumentasinya dalam 'Old Paris' yang menekankan pada imaji bentuk perspektif arsitektur yang didominasi oleh garis yang saling terhubung (tangential perspective) telah memberikan kesan pandang yang unik bernuansa surreal. Sementara itu, Henri Cartier Bresson (1908-2004) dalam salah satu karyanya "Madrid in 1933" menampilkan angle pemotretan ekstrem yang juga memberikan kesan perspektivis unik yang bernuansa surealistik dalam karya fotografinya.

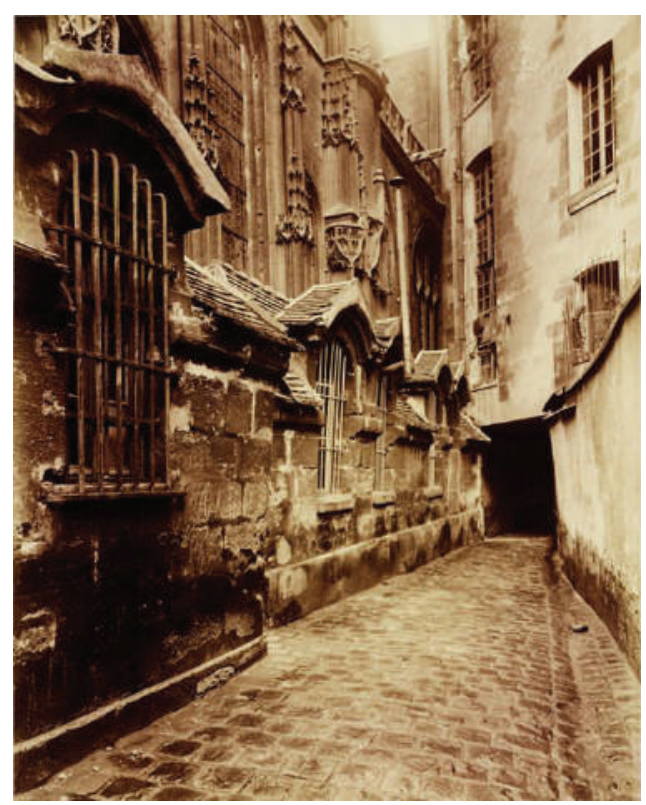

Gambar 10 E. Atget's “Church of St.Gervais”, c.1903, Paris

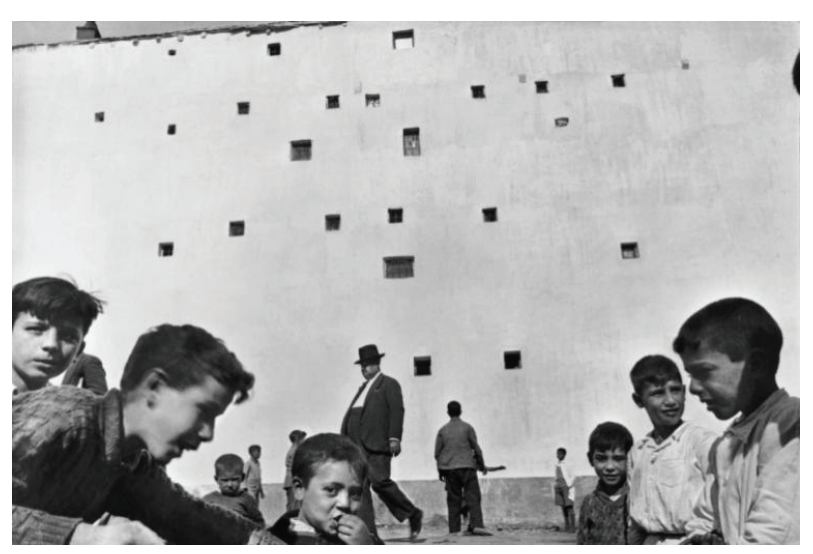

Gambar 11 Henri Cartier Bresson's 'Madrid in 1933', Madrid 1933, Spanyol 
Subjektivitas sang fotografer yang kreatif juga bisa menciptakan karya foto yang surealistis dengan memberdayakan berbagai teknik dalam ranah fotografi. Teknik yang dapat diberdayakan antara lain proses teknik pemotretan, teknik komposisi, teknik pencahayaan, dan teknik-teknik pemberdayaan menggunakan berbagai asesoris dari jenis dan ukuran lensa atau filter yang ada, berbagai perangkat lunak/softwares (PhotoShop, LightRoom, CorelDraw, etc.) dalam proses kamar gelap ataupun kamar terang (computer), sampai pada tahapan penampilan akhir bagaimana teknik sebuah karya foto itu dihadirkan untuk dipersepsi oleh publik. Di samping itu, kepekaan sang fotografer sebagai subjek perancang dan pencipta karya yang memiliki kepekaan estetis dan kreatifitas imajinatif untuk menciptakan imaji-imaji fotografi fantastis-imajinatif dalam berkarya sangatlah dibutuhkan untuk mendapatkan hasil karya fotografi yang bernuansa surealistis.

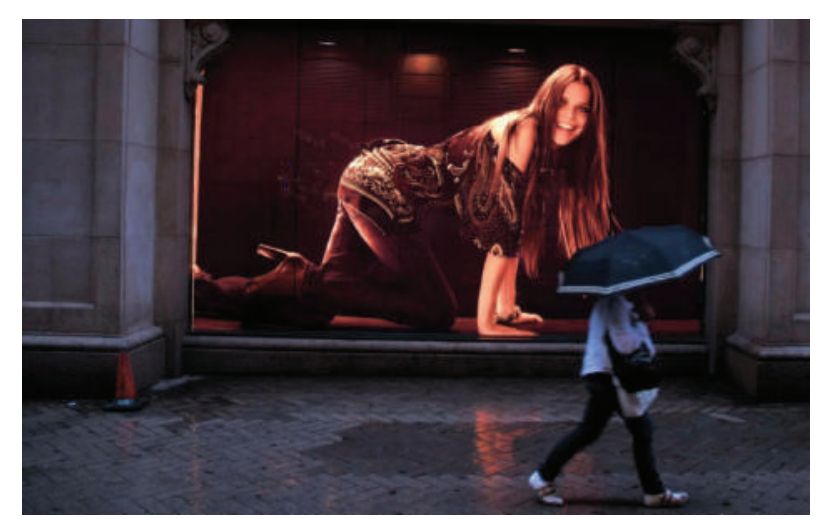

Gambar 12 “Umbrella”, (Barcelona 2008 - Soeprapto Soedjono)

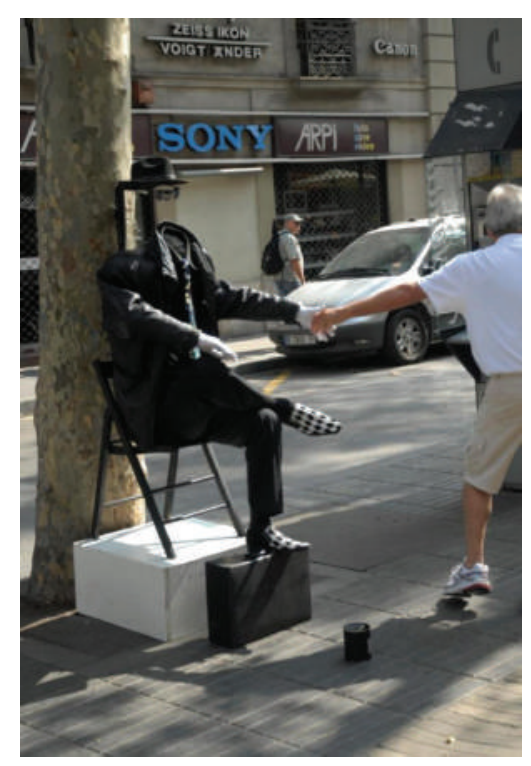

Gambar 13 “Hei..Wait...!”, (La Rambla, Barcelona, 2008 - soeprapto soedjono)

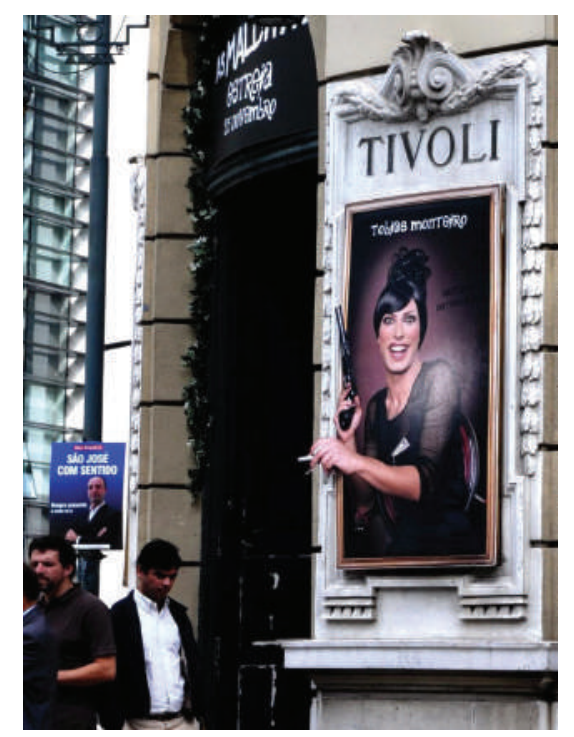

Gambar 14 "Street Trompe-l'oeil”, (Lizabon, 2008 Soeprapto Soedjono)

Dalam ranah wacana dan praksis fotografi, fotografi surealisme memiliki posisi yang unik dalam artibahwa awal kemunculannya mengikuti sejarah perkembangan seni rupa di Eropa. Adapun nilai-nilai filosofi dan estetikanya dilatarbelakangi oleh manifesto surealisme dari André Breton pada tahun 1924 serta beberapa teori transformasi dan realism $v s$ formalism dari Irving Singer, serta pengamatan fenomena post-auratic karya seni dan karya seni reproduksi dari Walter Benyamin. Ketiga tokoh yang memiliki perspektif pandang tentang nilai 
filosofis dan estetika tersebut telah memberikan kontribusi konsep penciptaan karya fotografi surealisme dengan perbedaan sikap kritis konsep yang saling melengkapi.

Dari sisi penciptaan karya fotografi, fotografi surealisme menawarkan sebuah konsep moda fotografi yang berlandaskan pada nilai estetika fotografi baik dalam tataran ideational maupun technical. Secara visual merupakan hasil ciptaan yang menawarkan sebuah bentuk tampilan karya fotografi yang kadang mengingkari nilai realisme faktual yang logis. Untuk itu, fotografi surealisme merupakan genre dalam fotografi ekspresi atau 'fine-arts photography' karena entitas visualnya tidak harus mengabdi pada kepentingan nilai dokumentatif faktual semata, tetapi juga telah menghadirkan ide dan konsep kebebasan berekspresi 'beyond photography' dalam karya fotografinya. Hal ini didukung oleh pernyataan Daniela Bowker tentang nilai teknis dan konsep penciptaannya yang dilengkapi oleh keutamaan dari sisi keluasan dan kedalaman sikap yang imajinatif dalam proses pelaksanaannya,

"Surreal photography can be as far removed from reality as you want it to be; it can be a fivedegree, or a five-mile shift away from the real world, and you can achieve either with whatever camera you have on hand... What's important is the richness and depth of your imagination" (Bowker, 2013:7).

\section{SIMPULAN}

Tuhan menciptakan segalanya sebagai realitas dan faktualitas alam sekitar yang memungkinkan untuk menjadi stimulus bagi manusia untuk bersikap kritis dan kreatif dalam mengembangkan penciptaan karya seninya yang didukung oleh kemampuan dalam mengangankan dan mengimajinasikannya dalam bentuk karya estetis visual dalam berbagai ragam matra yang ada. Salah satunya, telah tercipta dalam karya fotografi surealis dengan berbagai tampilan ide dan konsep kreatif estetisnya.

\section{KEPUSTAKAAN}

Benjamin, W. (1999). Illuminations. London: Pimlico-Random House.

Bowker, D. (2013). Surreal Photography, Creating the Impossible. New York \& London: Focal Press.

Clarke, G. (1997). The Photograph. Oxford, New York: Oxford University Press.

Fleming, W. (1980). Arts \& Ideas. New York: Holt, Rinehart, and Winston.

Jeffrey, I. (2008). How to Read a Photograph: Lessons from Master Photographers. New York: Harry N. Abrams, Inc.

Kress, Gunther \& Theo van Leeuwen. (1996). Reading Images: The Grammar of Visual Design, London: Routledge.

Marx, Kathryn. (1994). Right Brain Left Brain Photography: The Art and Technique of 70 Modern Masters, New York: Amphoto, Watson-Guptil Publications.

Maynard, Patrick. (1997). Thinking through Photography: The Engine of Visualization, Ithaca \& London: Cornell University Press.

Preble, D. \& S. (1989). Artsforms. New York: Harper \& Row, Publisher.

Singer, I. (1998). Reality Transformed, Film as Meaning and Technique. Cambridge, Massachusetts: The MIT Press.

Soedarso Sp. (2000). Sejarah Perkembangan SeniRupa Modern. Yogyakarta: BP ISI Yogyakarta.

(2006). Trilogi Seni: Penciptaan, Eksistensi dan Kegunaan Seni, Yogyakarta: BP. ISI Yogyakarta. 